\title{
Study on the Impact of Small Class Teaching on Students' Classroom Learning Behavior: Based on College English Teaching
}

\author{
Li Guo ${ }^{1}$ \\ ${ }^{1}$ Jiangxi Police College, Nanchang, Jiangxi, 330103
}

Keywords: small class teaching; classroom learning; College English teaching

\begin{abstract}
Learning is the basis of human beings, and learning to learn is even the most important part of the times. It is an inexhaustible motive force for sustainable human development. In the context of the new curriculum reform, small class teaching has emerged quietly. It has been called "a quiet revolution" and has created a good opportunity for students' development in theory and practice. Classroom teaching includes bilateral activities between teachers and students. Regardless of who is missing, the meaning of the class teaching is lacking. In order to make a deeper understanding of the reform of small class teaching, this paper takes the learning behavior of middle school students in small class as the basic research point, and pays attention to the process of realizing the learning behavior of students in small class teaching.
\end{abstract}

\section{Introduction}

There is no doubt that academic performance is related to learning behavior. In the above situation, teachers often change their teaching behavior to adapt to students' learning behavior to improve students' performance. This may be the responsibility of teachers. However, why don't we try to change our learning from the perspective of students? To achieve better teaching results and learning effects, it is well known that classroom teaching includes bilateral activities between teachers and students. Regardless of who is missing, the meaning of life in the classroom is lacking. Therefore, in the study of the classroom, we should not neglect the strength of students, ruthlessly deprive the students of their dominant position, and turn them into marginal subjects. Only by fundamentally solving the problem of students' "learning" and fully mobilizing the enthusiasm and initiative of students' learning and improving their learning ability, can the reform of education be full of vitality. In short, learning is the real goal of classroom teaching. Therefore, we should study student's learning behavior from the perspective of "actual", explore the nature of its changes under different teaching systems, and propose guiding strategies to improve the quality of classroom teaching instead of teachers' wishful thinking.

\section{Classification of Students' Learning Behavior in Small Class Teaching}

Listening is one of the main ways for people to acquire knowledge. Therefore, the author regards it as one of the dimensions of learning behavior, but listening and listening are two completely different concepts and cannot be compared. Listening is just a physiological process. It is the pure feeling of the auditory organ on sound waves and it is an unconscious act. Listening is not only a physiological sense of hearing, but also a positive, conscious auditory and psychological activity. By listening, you not only get information, but you can also understand emotions. Listening is an act of accepting all sorts of audible sounds with ears. It is only sound, no information, passive, unconscious actions. It mainly depends on objective and listening is an act of actively acquiring information. There is information, focusing on attention is a positive, conscious behavior that depends mainly on subjective awareness. In the traditional sense, people are accustomed to listening to and listening to teachers and arranging the equivalence. Obviously, this understanding is somewhat narrow. With the rapid development of science and technology and the continuous innovation of educational concepts, the connotation of listening is increasingly abundant. First of all, under the background of the new curriculum reform, the students' main status has been 
demonstrated. Students have their own right to speak in class teaching, and listening to students naturally becomes one of the main contents of listening. Second, the development of information technology and the application of multimedia in teaching make audio files one of the main contents of listening. Again, the interaction theory emphasizes the interaction between learners and texts. Zola said that "in front of the reader is not a bunch of black paper, but a person, a reader can hear his mind and mind jumping in the line between the words.” So reading the text is a dialogue with the text Listen to the voice of the author and the text. From the above explanation, it is known that listening in modern teaching covers listening to teachers, listening to students, and listening to texts from different dimensions of the subject.

Listening to teacher's teaching is one of the long-standing ways of learning. In the teaching process, teachers organize, process and organize teaching content in a targeted, organized, and planned manner. They adopt appropriate, varied and flexible teaching methods, impart knowledge, and produce knowledge. The teachers' knowledge and experience are richer than the students'. They inspire and guide the students and help students master knowledge, understand knowledge, and increase their minds. The constructivist view is that students do not go into the classroom with their heads empty. In the process of learning knowledge, students do not merely receive knowledge, but construct their meaning based on their own experience and understanding. Because of this, students' diversity of knowledge comprehension constitutes a rich source of learning resources. Students listen to their peers and constantly enrich, adjust, and enhance their own views. Therefore, listening to students is particularly important.

\section{Students' Learning Behavior in Small Class Teaching}

Dewey once compared the traditional education to "quiet listening education," a static word that exposes the drawbacks of traditional education to people in front of them, and makes communication a luxury in traditional classrooms. Under the modern teaching philosophy, the importance of communication is increasingly evident. Teaching without communication cannot be called teaching. Communication is the basis and prerequisite for teaching, and it is also one of the guarantees of teaching quality. Literally, communication refers to mutual communication, and the multi-directional communication in the text is related to the linear one-way communication between students and teachers, students and students in the traditional learning process. In traditional classroom teaching, communication is simply reflected in students receiving knowledge delivered by teachers or answering questions from teachers and peers. This form of communication is not material. Martin Buber believes that the real communication is manifested as "Every participant really has the present and the special presence of the other person or other person, and has the motivation to establish a living connection between himself and them. Turning to them." "However, because traditional classroom teaching has always been influenced by the main intellectualism, students are seen as a cognitive body in classroom teaching, rather than a complete and abundant living body. Teachers are the spokesperson of textbooks, classrooms The teaching process only duplicates and reproduces the knowledge of books, and the students only memorize and store the transmitted knowledge, because the students and the knowledge and the teachers often cannot really meet each other and cannot really communicate with each other. The closed circular movement of knowledge, meaningless generation, has become a barrier to student development to a certain extent. In the learning process, ideal communication should be a non-linear, multi-dimensional, multi-level dynamic interaction process. Students use text as an intermediary to interact with teachers and peers to promote the generation of meaning. This article starts from the perspective of students and communicates Different like, which form divided into four practice, i.e. self exchange, student exchange, life and exchange, this exchange students.

The ideal multi-directional communication is the intertwining of the four practice patterns in the learning process. Here, each individual consciously communicates with others. Here, the spirit is open, thinking is colliding, and the integration of others with vision. The four are closely linked and interpenetrated and intertwined to form a multi-level and multi-dimensional classroom exchange field. 


\section{Optimization Strategies of Students' Learning Behavior in Small Class Teaching}

As a hidden existence, concept has a tremendous impact on human behavior through cognitive structure and thinking. The root of its transformation is that the cognitive paradigm represented by the original concept has encountered a crisis of legitimacy. With the transformation of the traditional knowledge view to the postmodern knowledge view, the concept of education has changed one after another. The concrete manifestation is that the education concept moves from shaping the knowledge person to cultivating the happy person. The teaching concept changes from the knowledge professor to the conversational communication learning concept from the means of survival. Survive itself and so on. In order to highlight the essence of small classes and implement the teaching philosophy of small classes, teachers must fundamentally change educational concepts, establish new educational concepts, and build harmonious teacher-student relationships.

Classroom is a public space for learners to learn. It also woven their own personalities while acquiring knowledge. Classroom environment, as an educational factor that affects learning activities, should be conducive to the students' personal growth. When we entered the class of the small class, we deeply felt that the reduction of the class's hard work in the physical environment made the classroom bright and spacious, and the design of human nature made the environment more comfortable. A different kind of seating arrangement made learning more dynamic and cheerful. Bringing students into the arms of knowledge... Small classes create a good material foundation for students' learning. However, while optimizing the physical environment, they should also give full play to the educational function of the environment and make them become integrated into small class teaching concepts. To moisten the education function.

Stavelbem said that "the most important intention of the evaluation is not to prove it, but to improve it." "In today's quality education, the connotation of the word evaluation has changed throughout the entire classroom teaching process. Concerned about people's development, although the new curriculum is in full swing, students will never be able to escape a lifetime of bad luck. This not only distorts the main thrust of evaluation, but also deviates from the original intention of education. True, the quality of students is Can not be obtained only by quantitative evaluation, so we should change the evaluation system, from the results to the process, in the process of learning to discover and understand the students' potential and needs, to help students correctly self-perception, highlighting the student's individual freedom.

Academic analysis is an important component of instructional design. Accurately grasping the situation of learning enables teachers to perform in class and demonstrate teaching wisdom. In actual teaching, teachers often rely on their own experience to wishfully conceive students' actual status or in classroom teaching. Through the student's learning behavior, it is clear to diagnose the student's learning status. There are too many teachers from the teaching material point of view. Focus on the logical starting point of knowledge, while ignoring students' actual starting points. Effective academic analysis requires teachers to analyze students from multiple angles and understand students in all aspects. It not only pays attention to the starting point of knowledge in textbooks, but also pays attention to the students' own experience not only focusing on students' mastery of knowledge, but also responding to learning attitudes and learning methods. The evaluation of learning ability and learning effectiveness not only focuses on the current development status of the students, but also clearly recognizes the students' potential development needs. Only in this way can the learning situation be more comprehensive and systematic.

The academic situation is dynamic and developmental and changes according to the situation. The analysis of the academic situation starts before class, but does not stop before the class. The complete situation analysis should include the analysis of the situation before the class, the analysis of the situation in the class and the analysis of the situation after class. Pre-classification analysis represents the initial state of the student before entering the classroom and is the starting point for teachers to teach. With the development of classroom teaching, students' learning behaviors are constantly changing. Teachers should combine the dynamic presentation of learning behaviors in the classroom, constantly adjust the academic analysis before the lesson, and capture the underlying causes of learning behaviors to capture the underlying causes. Learning is more oriented. In the 
teaching process, because of the limitations of teaching time and teaching tasks, teachers may not have deep and thorough analysis of the academic situation. Therefore, after-school reflection is particularly important so that all students' information can be obtained. In short, the uncertainty of the academic situation makes it possible to analyze the academic situation at multiple levels.

\section{Conclusion}

Into the small class, gathered learning behavior, the author knows that the journey to explore learning behavior has begun. Before the departure, the author once feared that after worrying about the twists and turns of the journey and returning to the departure, my unique feelings of the scenery again and again made me fully loaded. Indeed, the research space for learning behaviors has caused me to forget to return. Although difficulties have been encountered in the research process, I still try to fully grasp the basic research points and insist on finding the lifeblood of the paper from practice to ensure the reliability and validity of the research results. Now, the journey is about to come to an end. The author intends to review and reflect on the entire journey.

\section{References}

[1] Wang Jianhua. On the Change of Ideas and Educational Transformation [J]. Education Guide. 2010 (09)

[2] Chen Lijuan. Analysis on Behavioral Characteristics of High School Outstanding Students [J]. New Composition (Education Teaching Research). 2009 (19)

[3] Yao Chunzhen, Mi Jianrong, Wang Hongcheng. An Overview of "Learning Behavior" Research at Home and Abroad [J]. Teaching and Management. 2009 (30)

[4] Yan Yulin. Effective regulation of cooperative learning in the process of small class teaching [J]. New Course (Teacher). 2009 (09)

[5] Lu Hongmei. Let students rejuvenate in the group cooperation-Talking about group cooperative learning in small class mathematics teaching [J]. Jilin Education. 2009 (20) 